\title{
VREG: A Virtual Reality Educational Game with Arabic Content Using Android Smart Phone
}

\author{
Saadeh Z. Sweidan, Khalid A. Darabkh \\ Department of Computer Engineering, The University of Jordan, Amman, Jordan \\ Email: s.sweadan@ju.edu.jo, k.darabkeh@ju.edu.jo
}

How to cite this paper: Sweidan, S.Z. and Darabkh, K.A. (2018) VREG: A Virtual Reality Educational Game with Arabic Content Using Android Smart Phone. Journal of Software Engineering and Applications, 11, 500-520.

https://doi.org/10.4236/jsea.2018.1110030

Received: September 20, 2018

Accepted: October 23, 2018

Published: October 26, 2018

Copyright $\odot 2018$ by authors and Scientific Research Publishing Inc. This work is licensed under the Creative Commons Attribution International License (CC BY 4.0).

http://creativecommons.org/licenses/by/4.0/

\begin{abstract}
In the last few decades, technology found its way from being a wild sci-fi dream, only seen in movies, to being an important element of all aspects of life. The technological industry bloomed quite rapidly where the technological solutions have made any process you can think of easier, faster and more efficient. Educational methodologies started off simple, having a teacher using simply his/her words and some writing along with it. With technology entering the field of education, teaching methods were enhanced and the quality of its outcomes was improved. However, sadly in Arab countries that was not the story. In other words, the use of new education technologies is still limited to basic and simple tasks. In fact, to add to the agony, most of the programs used are poorly implemented and rarely applied. Interestingly, as many studies confirm and from the simple observation of kids playing, it is found that most children are very attracted to new technologies and their applications. Those interests not only changed what a normal childhood would look like, but also introduced a multi-billion industry of electronic games. Virtual Reality (VR) games were introduced a few years back starting a gaming revolution, allowing gamers to enter the world of their dreams. Similar to most technologies, VR started to become more affordable with time. Multiple companies have competed to give us amazing VR products such as Samsung Gear. In this manuscript, we present a Virtual Reality Educational Game (VREG), which is an interactive 3D game with Arabic content that targets the students between age 4 and 8 and can be played on a smart phone. VREG includes multiple games that cover the different concepts of Arabic and English languages alongside math, aiming to help the student to learn through playing. In order to make sure that our game reaches wanted education standards, we put it to the test in two private schools; the feedback was very positive from both teachers and students where the majority of users enjoyed their experiments in VR games.
\end{abstract}




\section{Keywords}

Virtual Reality, Educational Games, Smart Phone Applications, Arabic Educational Applications, Interactive Learning

\section{Introduction}

In the last few years, communication technology has witnessed an enormous revolution [1]-[7]. Internet has become the backbone of the modern life by connecting people together [8]-[16], using devices like personal computers (PC's), tablets, smart phone which are provided commercially with many features and affordable prices [17]-[25]. Moreover, education benefitted to a great extent from this revolution allowing teachers to communicate with their students using a personal/official web site or through one of the many available smart phone applications (apps) [26]-[31].

The mechanism used is as follows, the student should be allowed to bring a tablet or a laptop to school as a study tool, following that soft copies of the books are downloaded and additional online resources are to be provided; as a result we are given the flexibility of being capable to present study material in new ways through software simulators or in the shape of animated videos, in addition to that we are protecting children's backs from the risk of an injury due to carrying heavy bags with printed books inside, exams can also be done online. These changes have broken the traditional teaching methods and introduced students to a new methodology of learning which is affective, interactive, and attractive. Consequently, technology in education has become a huge area of interest for many, and dozens of conferences are held to discuss this new trend worldwide.

Although electronic games appeared in the early 1950's as part of electric engineering labs researches, it was until 1970' when they started to get popular. That is because computers were very expensive at the time [32]. William Higginbotham would be credited to design and implement the first video game in 1958 in the Brookhaven National Laboratory. "Tennis for Two" is shown in Figure 1 [33]. However, it was Steve Russell who has created a game that inspired the multibillion dollar game industry we have today [34].

While the importance of electronic games has increased, different devices have appeared through which games can be played. Mainframe computer games were popular in the 1970s; however, large, graphics-decorated coin-operated arcade video games had their golden age between 1978 and 1982. Later on, popular and affordable home consoles (ex. ATARI) that are connected to TV have enabled people to play games inside home. During the 1980s, new concepts emerged like gaming computers, early online gaming and handheld LCD games [35]. More interestingly, game apps have appeared as a new popular form of gaming, games like candy crush and Pokémon Go have literally become an obsession for hundreds of millions around the globe. Over the past 50 years, electronic 


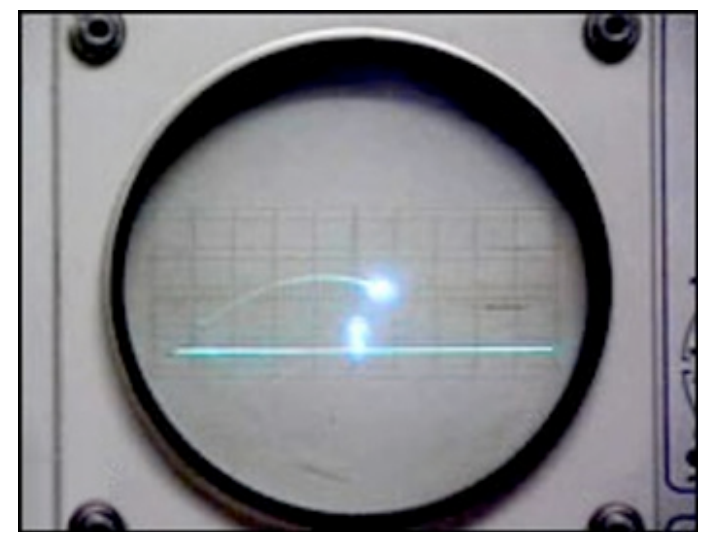

Figure 1. Tennis for two players the first electronic game [33].

games have become cultural aspect as one of the most popular media of choice between children and young adults. According to the entertainment software association, 59\% of Americans played video games in 2013 spending 21.5 billion dollars. The average American games player age is 31 years old and almost half of players are women [32]. In the middle East, four of ten people play video games regularly which make the area an attractive market for game developers [35].

On the other hand, smart phones have spread very fast during the last decade due to the remarkable features they offer such as the touch screen, big size screens, large memories, digital cameras and the ability to access the internet easily. As a result, the smart phone has become a necessary device carried often by most people and many apps were developed to work on them covering all aspects of life, for example, one can check the weather forecast for the day, buy groceries, chat with friends, book a movie ticket, or even play a game all through a smart phone [36] [37] [38] [39].

Virtual reality (VR) is an artificial environment that is presented to the user as a three-dimensional (3D) view which creates the illusion of being inside that environment instead of looking to a normal image [40] [41]. In order to generate realistic feeling, virtual reality is basically created on a computer targeting two senses: sight and sound in combination with physical spaces and multi-projected environments to simulate a physical presence in an imaginary environment. The person who uses virtual reality equipments will be able to "look around" the artificial world, move around it, and interact with virtual features or items. The effect is created using a head-mounted VR device which has a screen in front of the eyes.

In this paper, we introduce an Android smart phone educational game that is played on a VR console as a new learning tool we called it virtual reality educational game (VREG). The aim of this game is to help children between 4 and 8 years old to both learn and play in an interactive, colorful, three dimensional, full of animation, and sound effects environment. The rest of the paper is divided as follows, educational games concept, in addition to a related work com- 
parison which is shown in Section 2, Section 3 discusses the hardware components and the software tools we used to build the system, Section 4 describes the system design, while a run scenario is presented in Section 5, Section 6 tests the work and finally Section 7 concludes our work.

\section{Educational Games and Related Work}

The popularity of electronic games can be used in our favor to introduce unattractive study material to children, that would be by giving it as hidden messages in a shape of a fun game. In fact, educational games can motivate children to develop an awareness of consequentiality and to express themselves as individuals while learning and engaging in social issues. The first game to be considered as educational was developed in 1970 by Seymour Papert and Wally Fuerzeig and called Logo. The game blended mathematics and programming using a turtle-shaped cursor which is used to draw lines and create shapes [42]. However, the popular 1 game "Oregon Trail" which is shown in Figure 2, was released in 1971 to teach American geography and history where the player guides a family on their way across the country [43] [44] [45] [46].

Actually, using an interactive game to help a student learn has a number of recognized benefits. First of all, most students find games highly attractive and motivating. Moreover, games that provide real-life feedback and built-in goals can help students build their every day skills. In addition to that, students get the chance to make decisions as a part of the game and see the results of them right away which allows them to improve their future decisions. Even more, educational games can help players enhance coordination and visual skills as researchers from the University of Rochester in New York recently found [48] [49] [50] [51] [52]. In the study, frequent game players between the ages of 18 and 23 have shown better monitoring skills compared to those who didn't play as often or didn't play at all. They could keep track of multiple objects at a time and they were faster at picking out objects from a cluttered environment [53] [54] [55] [56].

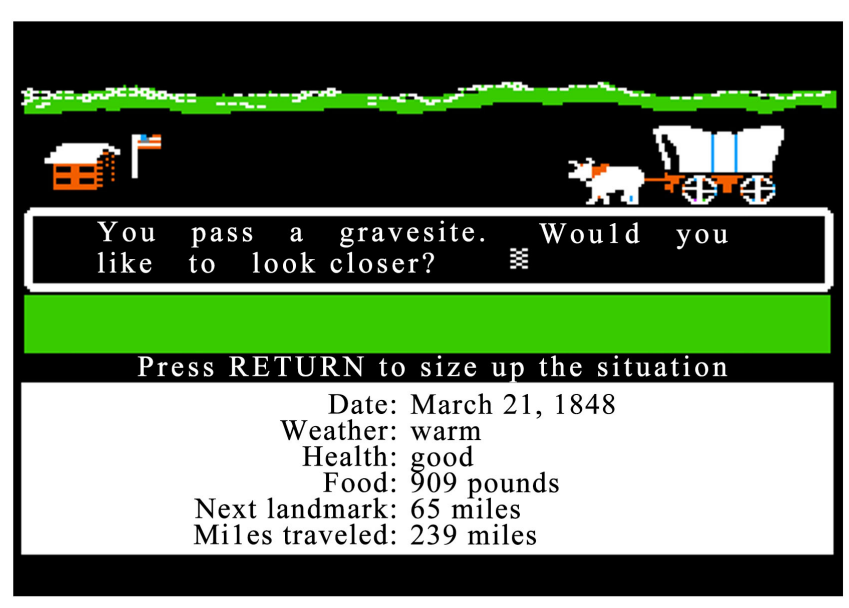

Figure 2. Oregon Trail game [47]. 
Nowadays, game developers focus on delivering games to users through different devices besides traditional game stations. Actually, it is very common to enter a web site using a personal computer and play an online game or even use a smart phone game app [57] [58]. This trend was very useful in easing the access to educational games at any time and any place instead of being exclusive to school labs. In this work we present a 3D game, which can be played on an Android smart phone connected to VR device to teach children basic math and linguistic skills for both Arabic and English in a colorful interactive environment with a wide range of ideas and using sound effects to transfer the user to an imaginary world, which makes learning fun. Some examples of other educational games are discussed next.

\subsection{First Game: Alarabia Alebtedaeaa}

Alarabia Alebtedaeaa is a very popular game app that is downloaded for free from the Google app store. The game basically teaches elementary school students Arabic language skills, in addition to basic counting skills. The game has three topics to select from as shown in Figure 3. The first topic teaches alphabets by showing the writing and pronunciation of each letter with example words on each of them. The second topic teaches the child to count and identify numbers using examples taken from surrounding environment. The last topic presents useful words to describe time, colors, fruits, animals, clothing, seasons and others [59]. The game is very basic and straightforward, easy to use, and efficient. Matter of fact, we compared this game to VREG and concluded the following points:

- Alarabia Alebtedaeaa's chosen method is based on direct lessons in the shape of simply animated pictures followed by direct questions related to each lesson with no score policy, VREG on the other hand, presented an untraditional teaching technique based on playing a full game where the questions must be answered to win and get a high score, which frees the child from the feeling of studying.

- Alarabia Alebtedaeaa covers Arabic language concepts and very limited counting skills compared to VREG which covers both Arabic and English languages, in addition to detailed math skills.

- Alarabia Alebtedaeaa uses classic graphics and characters shown in two dimension.

- (2D) pictures while VREG creates a full 3D environment to attract the user to the game.

\subsection{Second Game: Game Kids 2 Free}

Game Kids 2 Free can be installed from Android Play Store. The game is available in six languages and presents knowledge as a part of interesting colorful games breaking the traditional monotonous teaching methods for the ages between 4 and 7 years. Some of the topics covered in the game include ordering the 
numbers, math operation; addition and subtraction, Crayon drawing and coloring, Shapes discrimination and many more (Figure 4) [60]. The game can be compared to our work as the following:

- Both games introduce learning as a fun game with attractive graphics and sound effects. However, Game kids 2 uses only two dimensional pictures compared to the very attractive $3 \mathrm{D}$ views applied in VREG.

- Game kids 2 supports six languages not including Arabic which is spoken by hundreds of millions worldwide. On the other hand, VREG is basically a game with Arabic content and interface for Arabic children which also covers English which is essential to learn nowadays.

- The games in game kids 2 are traditional with no physical effort required while many VREG games force the student to jump, walk or rotate in an angle as a part of the game.

\section{Software Tools and Hardware Components}

VREG is built as a smart phone application. Unity is a free game engine and integrated development environment (IDE) introduced by unity technologies [61]. It is usually used to build high quality $3 \mathrm{D}$ and $2 \mathrm{D}$ games or interactive media for pc's, mobile devices, VR goggles, consoles like Xbox, and websites. Unity develops a game in two step operation; the first step includes using the Unity editor, while the second one uses $\mathrm{C \#}$ as a programming language [62] [63]. On the other hand, Maya is considered a powerful animation software application. It can be essentially used to create and edit 3D models to texture, animate, and final render multimedia products like video games, animated films or TV series. Moreover, Maya can run on Windows, Mac OS and Linux which provides a lot of flexibility to its user. It is designed to let you configure the user interface as you see it [64] [65] [66] [67].

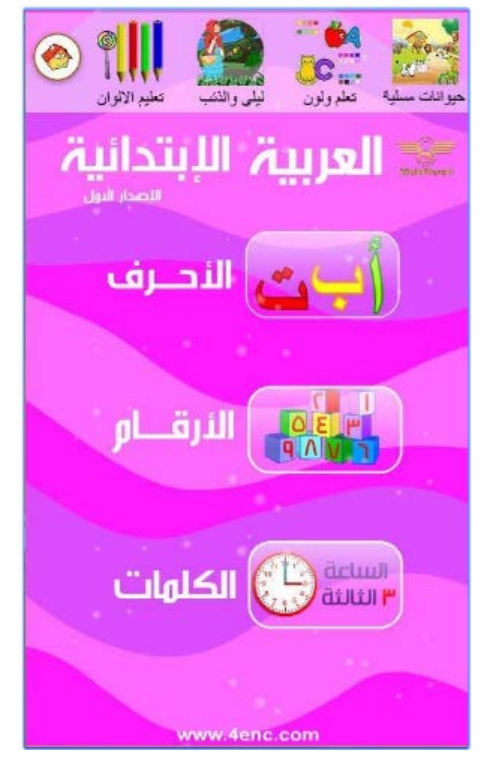

Figure 3. Alarabia Alebtedaeaa [59]. 


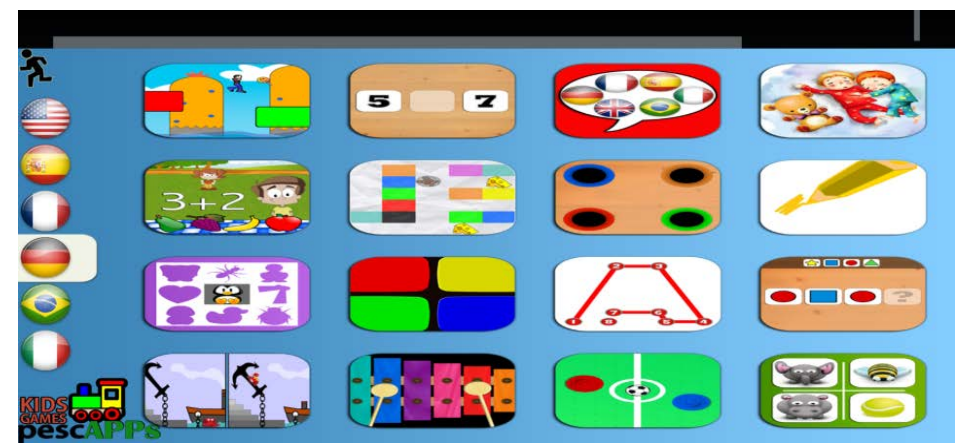

Figure 4. Game Kids 2 Free [60].

The game can be downloaded on a smart phone as an application from the Android play store. However, the phone must have a global system for mobile communication (GSM) chip so that it supports VR consoles. On the other hand, Oculus VR is an American technology company founded in July 2012 in Irvine, California, now based in Menlo Park [68]. It specializes in VR hardware and software products. Actually, two pre-production models were released to developers: the Oculus VR DK1 (Development Kit 1) and Oculus VR DK2 (Development Kit 2). The company also partnered with Samsung to develop the Samsung Gear VR in November 2015 for the Samsung Galaxy smart phones [69]. In our work, we have built the game to work basically on a Gear VR with the ability to work on other cheaper VR consoles but with lower resolution and Image quality compared to the Gear. The Gear VR provides a touch pad for communication and to make the $3 \mathrm{D}$ model more interactive. It also provides a head motions feature which displays the game in 360 degrees view and with a high resolution image [69] [70] [71].

\section{System Design}

The aim of the game is to guarantee the student participation in solving exercises related to basic courses, without even having the feeling that it is an obligatory homework. In fact, the learning part is hidden within a normal game, where the user has to win by getting a high score. Compared to traditional homework, which requires the student to hold a pencil or read a book to study. All that you need is to put on the VR console, that is connected to a smart phone and play the game. Moreover, VREG has multiple different games with different ideas to encourage students keep playing without feeling bored. Each game has its' own environment and way to play, for example, in one game the student has to shoot targets in the desert at sunset, while in another an underwater world is used to hide a fish among other sea creatures and so on. Furthermore, some games require physical effort such as jumping, rotating 360 degrees, or walking around (in a safe surrounding space of course) to break the old set and play concept. Different games with different environments and playing methods will hopefully attract the student to play and learn voluntarily without the feeling of undesirable obligation found in homework. Even more, playing a 3D game will create a 
colorful imaginary world that creates a realistic feeling of being in a desert or inside an ocean which makes playing more enjoyable and, of course, more useful.

Figure 5 shows the flow chart for using VREG. As we can see, the app interface starts with asking the user about his/her age to select suitable questions based on the expected student skills level. After that, the main menu appears where the student selects one of three courses to play, math, English, or Arabic. The following step is to select one of multiple games related to the chosen course like balloons, shooting, find the animal etc. ... At this point, the game starts with a series of problems to solve selected randomly from a questions bank, which is filled with questions divided into multiple categories and based on the course plus the student age. Each question appears as a written sentence on top of the screen along with current score and a timer for some games. If the student answers correctly, the score increases and a new question appears, otherwise, the score decreases and another chance is given to the student to answer the question. At the end of each game, the final score screen is shown before getting back to main menu where the students either selects a new course and game to play or exits the app.

English is the most common language in the world, either as a native tongue or as a second language. Moreover, it is the official language for the internet, science and international events [72]. As a major topic, VREG has a wide range of games with different difficulty levels according to the student's age. Some of the ideas included in English games are finding a letter, arranging some letters in alphabetical order, filling a word with a missing letter, matching a picture to a word, identifying a color or a naming the four seasons, an animal etc ...

On the other hand, Arabic is considered one of the most used languages with more than 300 million native speakers [73]. However, the Arabic online educational library is very poor, insufficient, and doesn't take full advantage of the new technologies available today. Actually, most of Arabic language e-learning content is presented mostly as a classical web site where the material is introduced in the shape of simple textual format with basic images or in the best case as straightforward videos or games with low graphics quality and direct information delivery methods. As a matter of fact, this form of presenting a lesson to a child does not differ a lot from reading a book. As a result of that, VREG's focus was to provide an interactive, rich graphic, colorful theme, indirect educational content for Arabic students using a 3D game.

Math is another essential topic for elementary school students that is covered in VREG. In fact, teaching math may be a real challenge for most students. It needs a lot of effort and requires practicing for a long time to gain the skill of doing mathematical operations like long division and fractions which makes it boring. VREG provides the luxury of practicing math as a fun game where the student plays to win and learn as well. The games related to math include counting numbers, comparing values, calculate a fraction, and many more. The next section presents a demo example of games related to language and math in order to show how the game actually works. 


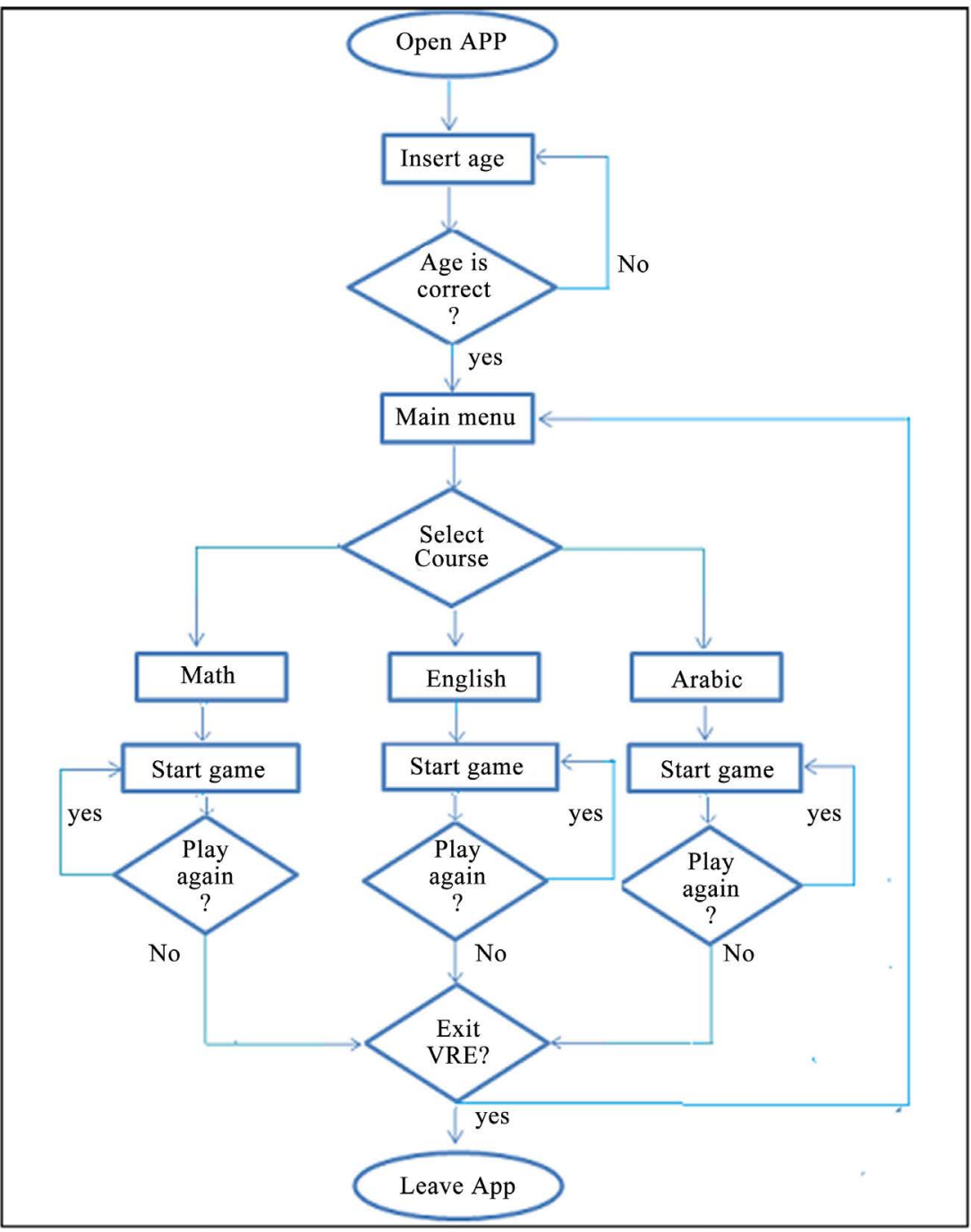

Figure 5. VREG working flow.

\section{VREG Run Scenario}

As mentioned earlier, the game has to be downloaded by the student or a parent on a smart phone and should be connected to a Samsung Gear console to play. When VREG runs, the home screen asks the about the players age between 4 and 8 years so that the games shown are only the ones with questions suitable for that age. As shown in Figure 6, the home screen background is a school building with a yellow school bus in front and titled as VR School to create an educational atmosphere that is convenient to the general theme.

After selecting the right age and confirming it, the student selects one of the three topics covered in the current version as shown in Figure 7. It is worth mentioning, that Arabic is the language used for written question and scores in Arabic language games, while English language games' questions and scores are written in English while math questions use both Arabic and English languages. Moreover, the questions in most games are shown as both written text and audio messages to help students who cannot read properly to play the game. 


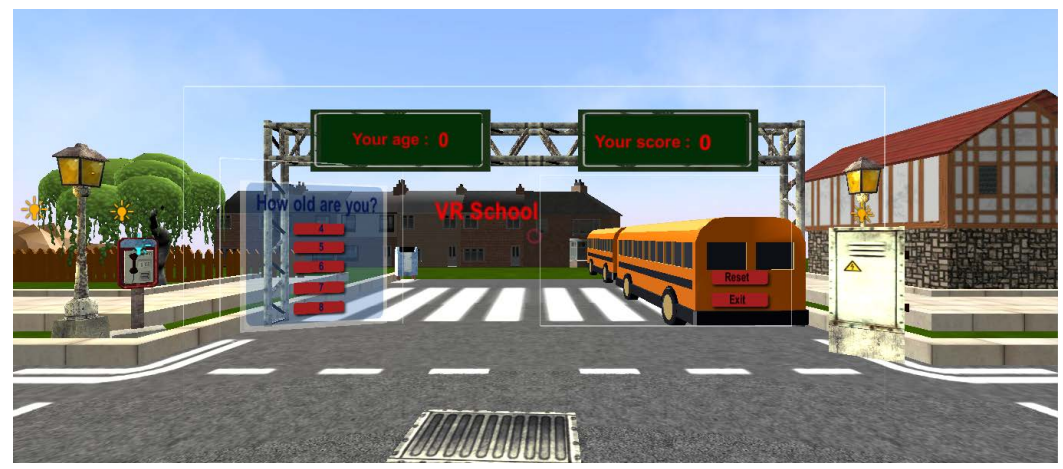

Figure 6. Home screen.

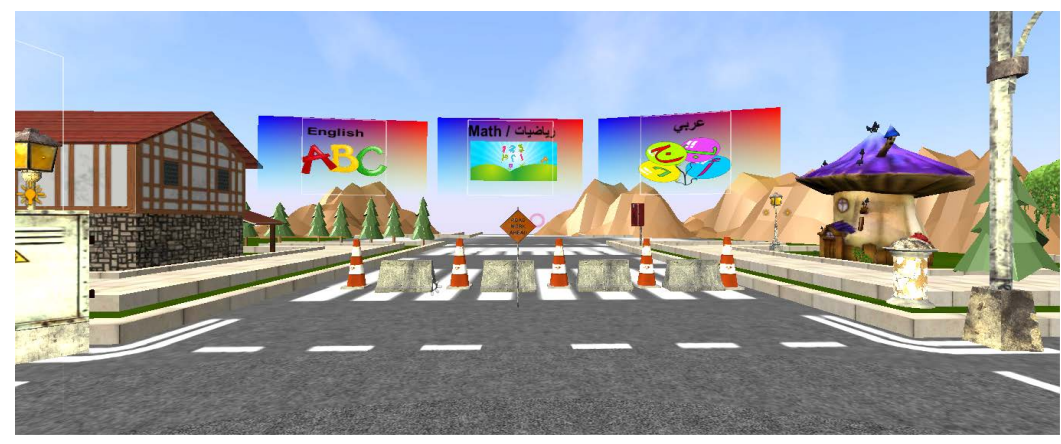

Figure 7. Select a topic to play screen.

Figure 8 shows an example of a math game called shooting numbers, where the student is asked to find the correct number and shoot the correct target between 4 choices in a western exciting theme. In this game, all the options are shown on the screen so there is no need for the player to rotate or move head up or down. It is an interesting fact to mention, that the Arabic language uses Indian numbers, whereas the English language uses Arabic numbers, hence, in this screen the Indian numbers are used for the question that is written and read as an audio in Arabic.

When a student shoots the wrong answer as in Figure 9, the total score decreases and the player is asked to try again. On the other hand, the correct answer is rewarded with extra points added to the current score and a new question appears. Each game consists of multiple questions with increasing difficulty levels. Furthermore, the questions are changed every time the game is played and chosen randomly from the VREG's question bank to avoid redundancy. After finishing any game, an end screen appears with the final score as can be noticed in Figure 10. Keeping track of score is very important in order to motivate the student to play again and improve it. Thus, the parent or the teacher can use the scores to measure the student's progress and determine the effectiveness of the game.

Figure 11 shows another game for the English language where the students is asked to identify a certain letter (A in this example) among multiple letters. A beach and sea theme is used with boats, birds and other colorful elements are mixed with the letters to make the game a little challenging and more attractive. 
As a matter of fact, this game screen uses 360 degree technology where the player has to rotate and move head up and down to find the answer. Additionally, VREG in many of its games forces the player to stand up, move, jump, and even walk a physical effort or exercise rather than passively set and play like most games. The only letters shown In Figure 11 are $\mathrm{K}$ and $\mathrm{N}$ but not $\mathrm{A}$, hence, the student has to look around left and right until A appears as in Figure 12.

Finally, we present an example of a game related to the Arabic content. Find the animal is a simple game where the student is asked to find a specific animal among four choices as in Figure 13 where monkey is the animal to find. The current score is 100 and it will increase if the answer is correct.

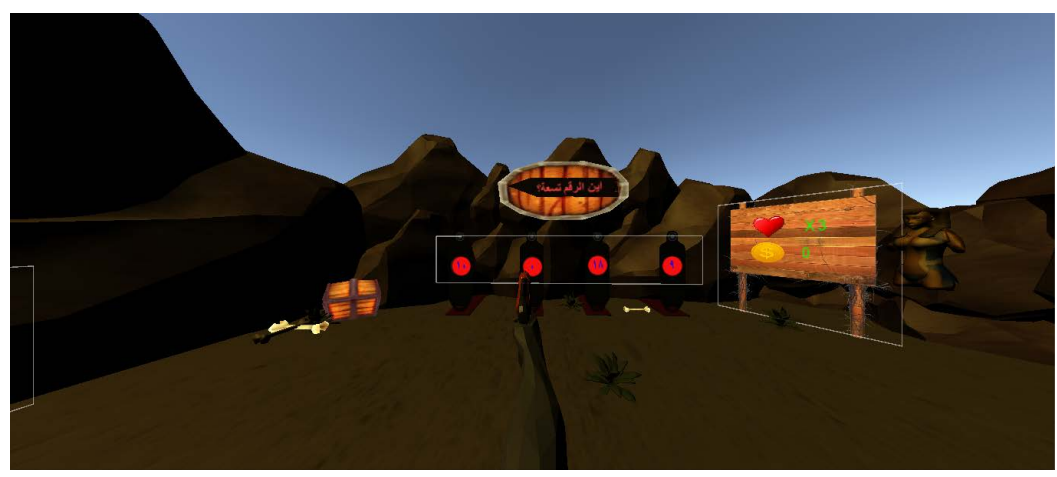

Figure 8. A math shooting game asks to find the digit 9.

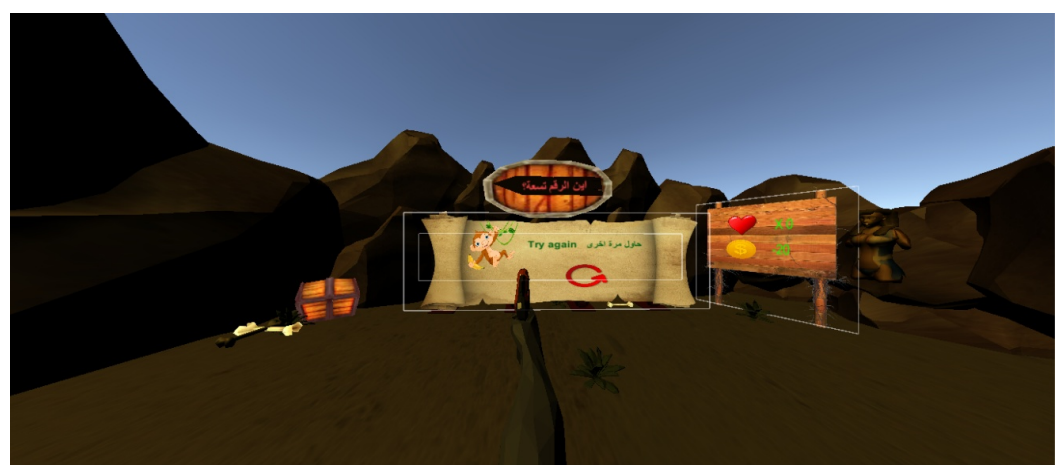

Figure 9. Math shooting game after a wrong answer.

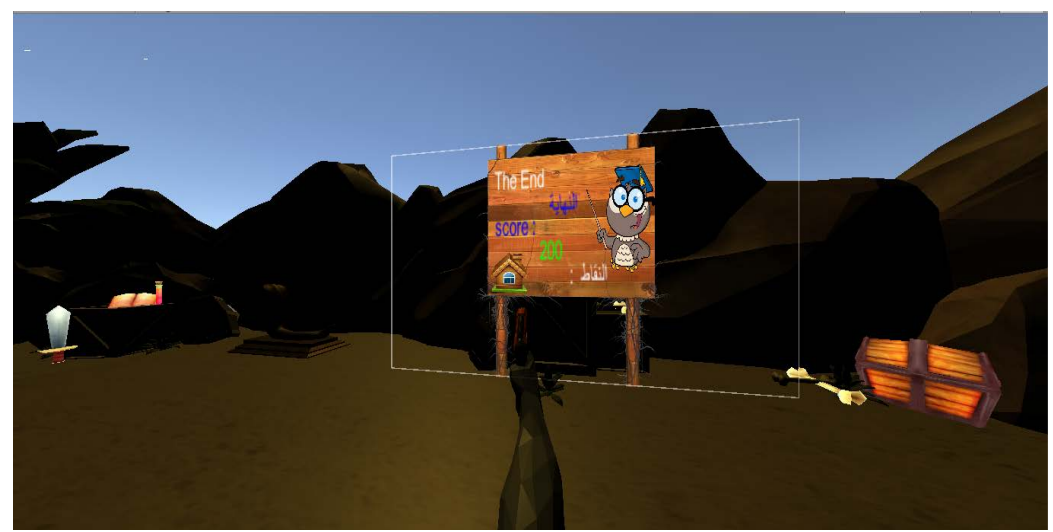

Figure 10. Math shooting game end screen with final score of 200 points. 


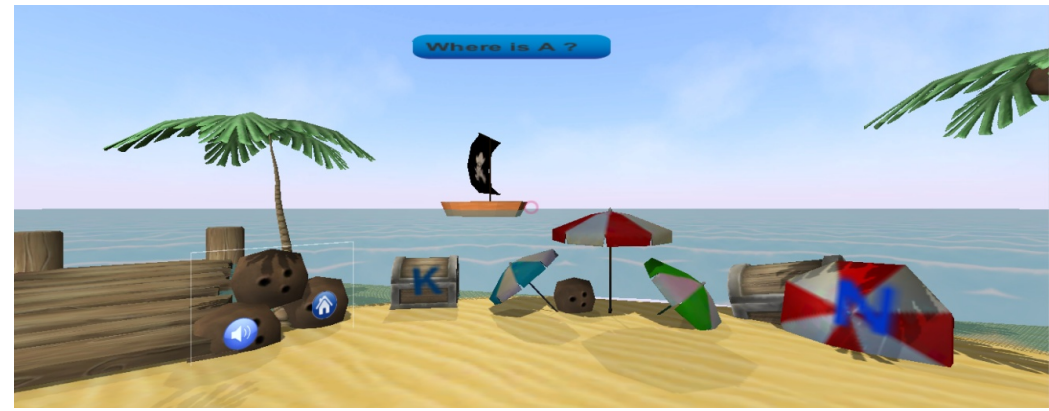

Figure 11. English language find a letter game with letter A not showing from the current angle.

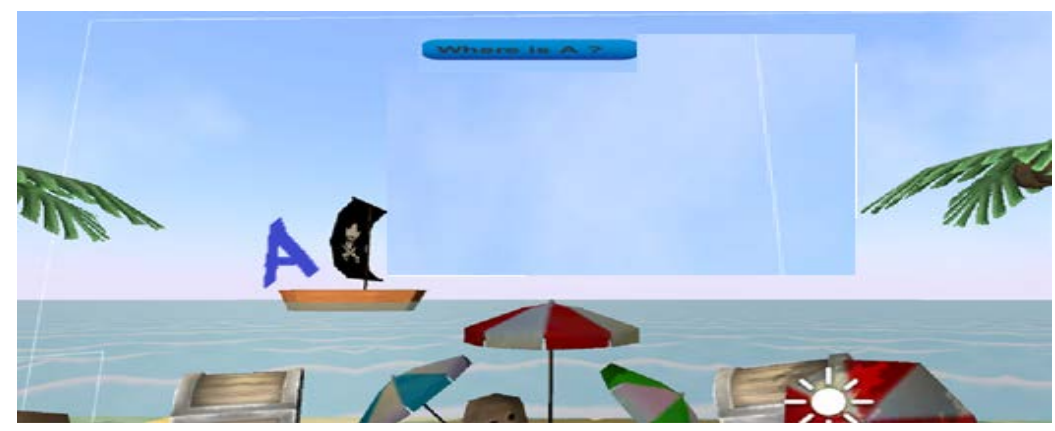

Figure 12. English language find a letter game with letter A appearing after the player rotates in an angle.

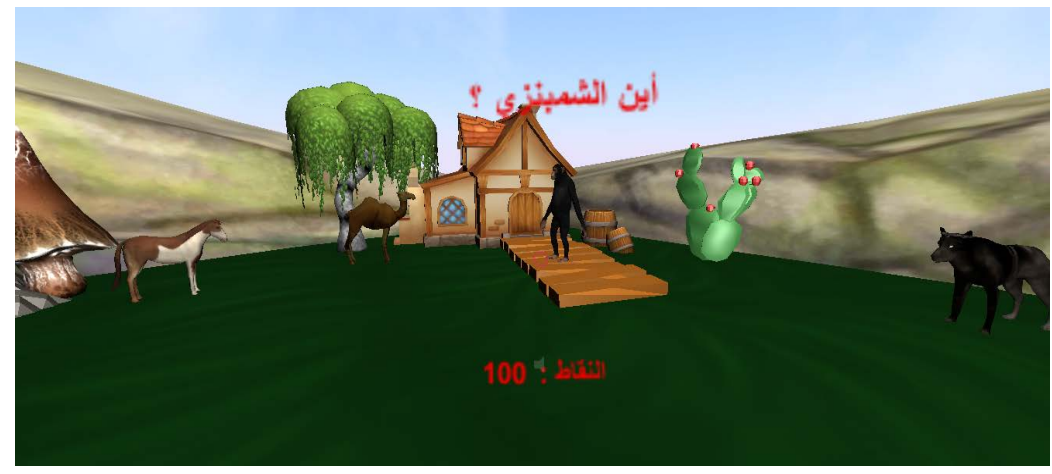

Figure 13. Arabic language game to find a monkey between other animals.

In addition to the mentioned examples, VREG has many more different games with various ideas and many themes. In fact, we have tested the game on a number of children and the responses were very promising. After that, we arranged multiple demo test events in a number of well-known private schools in Amman, Jordan. The results were beyond expected and the outcomes were very positive from both teachers and students. Most students enjoyed the game a lot and asked to have another turn to play. Even more, they said that they didn't feel that they were doing homework or studying. The teachers also had very encouraging opinions; one teacher was very excited to see some of the weakest students in math solving voluntarily mathematical operations through playing with a smile. Furthermore, teachers who adopted VREG to be used as a learning tool 
have reported that regular VREG players have shown a noticeable improvement in their linguistic and mathematic skills. On the other hand, the feedbacks included a number of useful suggestions that we plan to take into consideration to improve VREG like adding new topics and adding more animated objects.

\section{System Testing}

At this point we took our work and tested it in two well-known private schools, where both the students and the academic staff had the chance to play VREG games, the reactions and feedback were noticed and recorded. The aim of this was to study the direct effect of playing the game on the students and collect the reviews of their teachers from an academic point of view. Actually, the impressions were very promising, the students were excited to play the game and the teachers found the tool very useful and applicable as a supporting teaching method. In order to get more accurate outcomes, we asked both teachers and parents to fill a related survey after a week of using the app by the students in a regular manner. The survey included a free space for the users to write their impressions about VREG besides answering a number of questions to measure different points regarding educational games in general and VREG in specific.

Table 1 previews three samples of representative students' responses about their experiments in playing VREG. The three samples represent a high GPA student, an average student, and a struggling student, respectively. As we can see from the views, the tool has encouraged all students to do exercise even the ones with study challenges because they are presented in an attractive indirect way so the students are more involved in the learning process.

In a similar way, Table 2 shows a number of views taken from teachers based on their personal notes regarding their students' performance during playing the game and the improvement level they measured on their student's skills in math, Arabic, and English courses. Regarding some concerns about the unorthodox way of teaching and the fear of losing the special teacher-student connection, most teachers have shown very relieving views. Moreover, some of them admitted that playing the game has improved the skills of many students and engaged them more into learning. Over all, teachers can see VREG as an acceptable supporting teaching method.

The survey results are shown in Table 3. As mentioned earlier, the questions tried to collect the general view about educational games, alongside specific details about the user's experiments with VREG. The results have been very helpful to us in directing our future work and in measuring the general interest and understanding of the society to both educational games and VR products. The table shows 12 statements and the degree of agreement's percentage for each of them. The first three statements have shown that most people think the current teaching techniques adopted in schools are very boring to students and fail to attract them to study, also, more than $40 \%$ have a feeling that teachers give their students too much hard to do homework. Moreover, the majority thinks that children in general are very attached to smart phone applications. 
Table 1. Representative students view after trying VREG.

\begin{tabular}{|c|c|}
\hline Student 1 & $\begin{array}{l}\text { "The game was interesting, full of different ideas, fun to play, and very } \\
\text { useful to practice mathematical operations in a new way" }\end{array}$ \\
\hline Student 2 & $\begin{array}{l}\text { "It is funny to play instead of studying, I can do this for hours unlike } \\
\text { boring home works" }\end{array}$ \\
\hline Student 3 & $\begin{array}{l}\text { "For the first time I enjoy math exercises and English words learning, it } \\
\text { is not a problem for me to solve my home works if I can play the game } \\
\text { to do them" }\end{array}$ \\
\hline Teacher 1 & $\begin{array}{l}\text { "VREG is a revolutionary tool to attract students to the class, it can be } \\
\text { used as a part of most classes as an additional teaching tool" }\end{array}$ \\
\hline Teacher 2 & $\begin{array}{l}\text { "The game is interesting to play, it can help but it shouldn't replace the } \\
\text { teacher student regular teaching operation" }\end{array}$ \\
\hline Teacher 3 & $\begin{array}{l}\text { "I have never expected to see one of my weakest students so enthusiastic } \\
\text { to solve math exercises through the game, I don't think he is aware that } \\
\text { he is learning while playing, but the important thing that I can see a } \\
\text { noticeable improvement in his math skills along with other students as } \\
\text { well" }\end{array}$ \\
\hline
\end{tabular}

Table 3. Survey statements and their agreement percentage.

\begin{tabular}{|c|c|c|c|c|}
\hline No. & \multicolumn{4}{|c|}{ Survey question } \\
\hline & \multicolumn{4}{|c|}{ Current teaching methods are unattractive for students } \\
\hline \multirow[t]{3}{*}{1} & SA & $\mathrm{AC}$ & NAND & $\mathrm{D}$ \\
\hline & $19 \%$ & $48 \%$ & $4 \%$ & $29 \%$ \\
\hline & \multicolumn{4}{|c|}{ Home works quantity and quality are over students ability to handle } \\
\hline \multirow[t]{3}{*}{2} & SA & $\mathrm{AC}$ & NAND & $\mathrm{D}$ \\
\hline & $10 \%$ & $33 \%$ & $5 \%$ & $52 \%$ \\
\hline & \multicolumn{4}{|c|}{ Most children are very attached to smart phone applications } \\
\hline \multirow[t]{3}{*}{3} & SA & $\mathrm{AC}$ & NAND & $\mathrm{D}$ \\
\hline & $66 \%$ & $24 \%$ & $6 \%$ & $4 \%$ \\
\hline & \multicolumn{4}{|c|}{ Using technology in education is useful for teachers and students } \\
\hline \multirow[t]{3}{*}{4} & SA & $\mathrm{AC}$ & NAND & $\mathrm{D}$ \\
\hline & $52 \%$ & $38 \%$ & $3 \%$ & $7 \%$ \\
\hline & \multicolumn{4}{|c|}{$\begin{array}{l}\text { Educational games as supporting teaching tools are logically } \\
\text { and ethically acceptable }\end{array}$} \\
\hline \multirow[t]{3}{*}{5} & SA & $\mathrm{AC}$ & NAND & $\mathrm{D}$ \\
\hline & $33 \%$ & $48 \%$ & $5 \%$ & $14 \%$ \\
\hline & \multicolumn{4}{|c|}{ VREG has motivated students to learn and solve exercises } \\
\hline \multirow[t]{2}{*}{6} & SA & $\mathrm{AC}$ & NAND & $\mathrm{D}$ \\
\hline & $33 \%$ & $57 \%$ & $5 \%$ & $5 \%$ \\
\hline 7 & \multicolumn{4}{|c|}{$\begin{array}{l}\text { Playing VREG regularly has improved students' } \\
\text { mathematical and linguistic skills }\end{array}$} \\
\hline
\end{tabular}




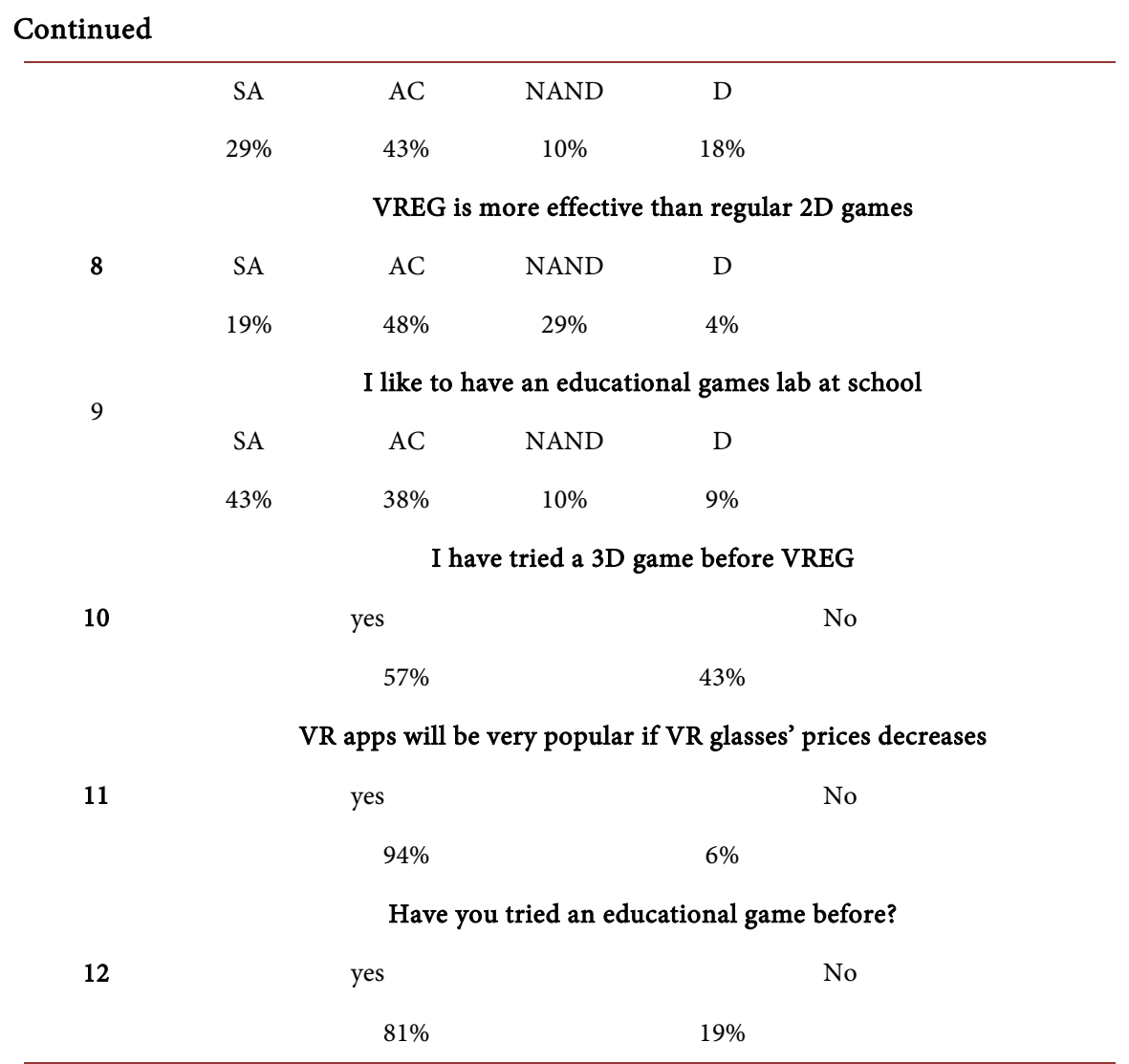

$\mathrm{SA}=$ Strongly agree, $\mathrm{AC}=$ Agree with concerns, $\mathrm{NAND}=$ Neither agree nor disagree, $\mathrm{D}=$ Disagree.

On the other hand, the feedback for statements 4 to 8 has shown a real belief in the importance of including new technologies in the teaching process and without having any ethical or educational constrains. Even more, the feedback of using VREG in classes was very promising and exceeded our expectations. Most teachers have agreed that their students were very motivated to solve exercises when asked to wear the Samsung VR gear and play the game. Moreover, the regular using of VREG for a week has noticeably improved both the linguistic and mathematical skills for students as most teachers answered. Actually, adding the 3D feature to VREG has relatively made it more attractive for the students to play compared to regular 2D games as statement 8 outcomes suggested and most teachers agreed. The total experiment effect can be concluded through statement 9, where the results were very positive with noticeable acceptance ratio to the idea of installing an educational games laboratory in the school.

Finally, statements 10 to 12 tried to measure the previous experience of our survey target sample in both VR technology and educational games fields. As the numbers show, more than half of the survey fillers have tried a 3D game before and over $80 \%$ of them have a previous experiment with educational games. Moreover, almost all of them agreed that VR technology will be more popular if the prices of VR glasses become more affordable which is very expected to happen in the next few years. 


\section{Conclusion}

Technology has become an essential part of all modern life aspects including education. Most countries worldwide have adopted new policies in order to take advantage of the internet and new communication trends like PC's, tablets, smart phones apps, social networks, and others, in order to enhance the learning process and to make it more attractive and interactive for students. However, Arabic language is poorly represented in modern education technologies despite the fact that it is one of the most common languages in the world. Moreover, electronic game is a massive industry presented in different forms and very popular between children and adults. VR is a way to present a 3D image for the user to create an imaginary world to simulate a real environment. Although it is not new, the importance of VR applications has remarkably increased in the last few years. Furthermore, many companies have commercially provided a number of portable VR consoles which helped in increasing the popularity of 3D products like movies or games. In our work, we used Samsung Gear VR console connected to a smart phone in order to present an educational game app for students in the age between 4 and 8 years old called VREG. The app covers Arabic, English and math courses as a first phase and provides multiple games for each course, where different themes are used like the desert, the beach, the ocean, and many more to create a variety of playing environments. When the installed VREG app runs, it asks about the student's age to select age suitable questions in any chosen game; after that, the student has to select a course and a game to play. The game is played by solving a series of questions one at the time until the level ends. If the answer to a certain question is correct, the score increases, else it decreases and the student is asked to try again. Moreover, the game has been tested in two schools where students were asked to play different games in the app and asked to evaluate them. The responses were very positive from both students and teachers and useful notes were presented. As a future work, we plan to extend the game into other courses and for larger ages to build a complete interactive play and learn system for Arabic students.

\section{Acknowledgements}

The authors would like to thank the students who provided their feedback instantaneously and have built some of the tools used in this work, particularly, Delana Kurdi, and Afnan Habahbeh.

\section{Funding}

This study is not funded.

\section{Ethical Approval}

All procedures performed in studies involving human participants were in accordance with the ethical standards of the institutional and/or national research committee and with the 1964 Helsinki declaration and its later amendments or 
comparable ethical standards.

\section{Conflicts of Interest}

The authors declare no conflicts of interest regarding the publication of this paper.

\section{References}

[1] Al-Mistarihi, M.F., Mohaisen, R., Sharaqa, A., Shurman, M.M. and Darabkh, K.A. (2015) Performance Evaluation of Multiuser Diversity in Multiuser Two-Hop Cooperative Multi-Relay Wireless Networks Using MRC over Rayleigh Fading Channels. International Journal of Communication Systems, 28, 71-90.

https://doi.org/10.1002/dac. 2640

[2] Darabkh, K.A., Awad, A.M. and Khalifeh, A.F. (2015) New Video Discarding Policies for Improving UDP Performance over Wired/Wireless Networks. International Journal of Network Management, 25, 181-202. https://doi.org/10.1002/nem.1888

[3] Darabkh, K.A., Al-Rawashdeh, W.S., Al-Zubi, R.T. and Alnabelsi, S.H. (2017) A New Cluster Head Replacement Protocol for Wireless Sensor Networks. Proceedings of 2017 IEEE European Conference on Electrical Engineering \& Computer Science, Bern, 17-19 November 2017, 472-476.

https://doi.org/10.1109/EECS.2017.93

[4] Darabkh, K.A. and EL-Yabroudi, M.Z. (2017) A Reliable Relaying Protocol in Wireless Sensor Networks. Proceedings of 2017 IEEE European Conference on Electrical Engineering \& Computer Science, Bern, 17-19 November 2017, 56-60. https://doi.org/10.1109/EECS.2017.20

[5] Khalifeh, A., Darabkh, K.A. and Kamel, A. (2012) Performance Evaluation of Voice-Controlled Online Systems. Proceedings of IEEE/SSD'12 Multi-Conference on Systems, Signals, and Devices, Chemnitz, 20-23 March 2012, 1-6. https://doi.org/10.1109/SSD.2012.6198087

[6] Darabkh, K.A. and Abu-Jaradeh, B. (2010) Bounded Fano Decoders over Intermediate Hops Excluding Packet Retransmission. Proceedings of IEEE 24th International Conference on Advanced Information Networking and Applications (AINA 2010), Perth, 20-13 April 2010, 299-303. https://doi.org/10.1109/AINA.2010.141

[7] Darabkh, K.A. and Abu-Jaradeh, B. (2010) Buffering Study over Intermediate Hops including Packet Retransmission. Proceedings of IEEE International Conference on Multimedia Computing and Information Technology (MCIT-2010), Sharjah, 2-4 March 2010, 45-48. https://doi.org/10.1109/MCIT.2010.5444857

[8] Darabkh, K.A., Awad, A.M. and Khalifeh, A.F. (2014) Efficient PFD-Based Networking and Buffering Models for Improving Video Quality over Congested Links. Wireless Personal Communications, 79, 293-320. https://doi.org/10.1007/s11277-014-1857-1

[9] Darabkh, K.A., Ibeid, H., Jafar, I.F. and Al-Zubi, R.T. (2016) A Generic Buffer Occupancy Expression for Stop-and-Wait Hybrid Automatic Repeat Request Protocol over Unstable Channels. Telecommunication Systems, 63, 205-221. https://doi.org/10.1007/s11235-015-0115-5

[10] Darabkh, K.A. and Pan, W.D. (2006) Stationary Queue-Size Distribution for Variable Complexity Sequential Decoders with Large Timeout. Proceedings of the $44^{\text {th }}$ ACM Southeast Conference, Melbourne, 10-12 March 2006, 331-336.

[11] Darabkh, K.A. and Aygun, R.S. (2006) Quality of Service and Performance Evalua- 
tion of Congestion Control for Multimedia Networking. Proceedings of 2006 International Conference on Internet Computing (ICOMP06), Las Vegas, 26-29 June 2006, 217-223.

[12] Darabkh, K.A., Al-Maaitah, N.J., Jafar, I.F. and Khalifeh, A.F. (2018) EA-CRP: A Novel Energy-Aware Clustering and Routing Protocol in Wireless Sensor Networks. Computers and Electrical Engineering, In Press.

[13] Darabkh, K.A., Al-Rawashdeh, W.S., Al-Zubi, R.T. and Alnabelsi, S.H. (2017) C-DTB-CHR: Centralized Density- and Threshold-Based Cluster Head Replacement Protocols for Wireless Sensor Networks. Journal of Supercomputing, 73, 5332-5353. https://doi.org/10.1007/s11227-017-2089-4

[14] Darabkh, K.A., Abu-Jaradeh, B. and Jafar, I. (2011) Incorporating Automatic Repeat Request and Thresholds with Variable Complexity Decoding Algorithms over Wireless Networks: Queuing Analysis. IET Communications, 5, 1377-1393. https://doi.org/10.1049/iet-com.2010.0698

[15] Darabkh, K.A. (2011) Evaluation of Channel Adaptive Access Point System with Fano Decoding. International Journal of Computer Mathematics, 88, 916-937. https://doi.org/10.1080/00207160.2010.485249

[16] Darabkh, K.A. (2010) Queuing Analysis and Simulation of Wireless Access and End Point Systems Using Fano Decoding. Journal of Communications, 5, 551-561. https://doi.org/10.4304/jcm.5.7.551-561

[17] Darabkh, K.A., Albtoush, W.Y. and Jafar, I.F. (2017) Improved Clustering Algorithms for Target Tracking in Wireless Sensor Networks. Journal of Supercomputing, 73, 1952-1977. https://doi.org/10.1007/s11227-016-1898-1

[18] Al-Dhamari, A.K. and Darabkh, K.A. (2017) Block-Based Steganographic Algorithm Using Modulus Function and Pixel-Value Differencing. Journal of Software Engineering and Applications, 10, 56-77. https://doi.org/10.4236/jsea.2017.101004

[19] Darabkh, K.A. (2014) Imperceptible and Robust DWT-SVD-Based Digital Audio Watermarking Algorithm. Journal of Software Engineering and Applications, 7, 859-871. https://doi.org/10.4236/jsea.2014.710077

[20] Darabkh, K.A., El-Yabroudi, M.Z. and El-Mousa, A.H. (2019) BPA-CRP: A Balanced Power-Aware Clustering and Routing Protocol for Wireless Sensor Networks. Ad Hoc Networks, 82, 155-171. https://doi.org/10.1016/j.adhoc.2018.08.012

[21] Darabkh, K.A., Judeh, M.S.A., Salameh, H.B. and Althunibat, S. (2018) Mobility Aware and Dual Phase AODV Protocol with Adaptive Hello Messages over Vehicular Adhoc Networks. International Journal of Electronics and Communications, 94, 277-292. https://doi.org/10.1016/j.aeue.2018.07.020

[22] Darabkh, K.A., Al-Rawashdeh, W.S., Hawa, M. and Saifan, R. (2018) MT-CHR: A Modified Threshold-Based Cluster Head Replacement Protocol for Wireless Sensor Networks. Computers and Electrical Engineering. https://doi.org/10.1016/j.compeleceng.2018.01.032

[23] Darabkh, K.A. and Alsukour, O. (2015) Novel Protocols for Improving the Performance of ODMRP and EODMRP over Mobile Ad Hoc Networks. International Journal of Distributed Sensor Networks, 2015, Article ID: 348967. https://doi.org/10.1155/2015/348967

[24] Darabkh, K.A. and Al-Jdayeh, L. (2018) A New Fixed Clustering Based Algorithm for Wireless Sensor Networks. Proceedings of the 14th IEEE International Wireless Communications and Mobile Computing Conference, Limassol, 25-29 June 2018, 71-76. https://doi.org/10.1109/IWCMC.2018.8450485 
[25] Darabkh, K.A. and Zomot, J.N. (2018) An Improved Cluster Head Selection Algorithm for Wireless Sensor Networks. Proceedings of the 14th IEEE International Wireless Communications and Mobile Computing Conference, Limassol, 25-29 June 2018, 65-70.

[26] Darabkh, K.A. and Judeh, M.S.E. (2018) An Improved Reactive Routing Protocol over Mobile Ad-Hoc Networks. Proceedings of the 14th IEEE International Wireless Communications and Mobile Computing Conference, Limassol, 25-29 June 2018, 707-711.

[27] Qaralleh, E.A. and Darabkh, K.A. (2015) A New Method for Teaching Microprocessors Course Using Emulation. Computer Applications in Engineering Education, 23, 455-463. https://doi.org/10.1002/cae.21616

[28] Swiedan, S.Z. and Darabkh, K.A. (2015) A New Efficient Assembly Language Teaching Aid for Intel Processors. Computer Applications in Engineering Education, 23, 217-238. https://doi.org/10.1002/cae.21591

[29] Abandah, G.A., Darabkh, K.A., Ammari, T. and Qunsul, O. (2014) Secure National Electronic Voting System. Journal of Information Science and Engineering, 30, 1339-1364.

[30] Darabkh, K.A., Haddad, L., Swiedan, S.Z., Hawa, M., Saifan, R. and Alnabelsi, S.H. (2018) An Efficient Speech Recognition System for Arm-Disabled Students Based on Isolated Words. Computer Applications in Engineering Education, 26, 285-301. https://doi.org/10.1002/cae.21884

[31] Darabkh, K.A., Haddad, L. and Sweidan, S. (2017) A Modified Speech Recognition Algorithm for People with Physical Disabilities. Proceedings of 2017 IEEE European Conference on Electrical Engineering \& Computer Science, Bern, 23-27.

https://doi.org/10.1109/EECS.2017.13

[32] Egenfeldt-Nielsen, S., Smith, J.H. and Tosca, S.P. (2015) Understanding Video Games: The Essential Introduction. Routledge, Abingdon-on-Thames. https://doi.org/10.4324/9781315725161

[33] https://www.pcworld.com/article/153548/first_video_game.html

[34] Gee, J.P. (2005) Learning by Design: Good Video Games as Learning Machines. E-Learning and Digital Media, 2, 5-16.

[35] Thompson, D., Baranowski, T., Buday, R., Baranowski, J., Thompson, V., Jago, R. and Griffith, M.J. (2010) Serious Video Games for Health: How Behavioral Science Guided the Development of a Serious Video Game. Simulation \& Gaming, 41, 587-606. https://doi.org/10.1177/1046878108328087

[36] Shin, D.-H. (2014) Measuring the Quality of Smartphones: Development of a Customer Satisfaction Index for Smart Services. International Journal of Mobile Communications, 12, 311-327. https://doi.org/10.1504/IJMC.2014.063650

[37] Shin, D.-H., Shin, Y.-J., Choo, H. and Beom, K. (2011) Smartphones as Smart Pedagogical Tools: Implications for Smartphones as u-Learning Devices. Computers in Human Behavior, 27, 2207-2214. https://doi.org/10.1016/j.chb.2011.06.017

[38] Stefani, L., Mason, R. and Pegler, C. (2007) The Educational Potential of e-Portfolios: Supporting Personal Development and Reflective Learning. Routledge, Abingdon-on-Thames. https://doi.org/10.4324/9780203961292

[39] Raento, M., Oulasvirta, A. and Eagle, N. (2009) Smartphones: An Emerging Tool for Social Scientists. Sociological Methods \& Research, 37, 426-454.

[40] Darabkh, K.A., Alturk, F.H. and Sweidan, S.Z. (2018) VRCDEA-TCS: 3D Virtual Reality Cooperative Drawing Educational Application with Textual Chatting Sys- 
tem. Computer Applications in Engineering Education, 26, 1677-1698.

[41] Sweidan, S.Z., Saifan, R., Darabkh, K.A. and Abu-Kaff, S. (2017) Kids' Tracker: An Android Application for Tracking Children. Journal of Software Engineering and Applications, 10, 907-924. https://doi.org/10.4236/jsea.2017.1013052

[42] Gee, J.P. (2003) What Video Games Have to Teach Us about Learning and Literacy. Computers in Entertainment, 1, 20. https://doi.org/10.1145/950566.950595

[43] Shaffer, D.W., Squire, K.R., Halverson, R. and Gee, J.P. (2005) Video Games and the Future of Learning. Phi Delta Kappan, 87, 105-111.

[44] Prensky, M. (2003) Digital Game-Based Learning. Computers in Entertainment, 1, 21. https://doi.org/10.1145/950566.950596

[45] Greenfield, P., De Winstanley, P., Kilpatrick, H. and Kaye, D. (1994) Action Video Games and Informal Education: Effects on Strategies for Dividing Visual Attention. Journal of Applied Developmental Psychology, 15, 105-123. https://doi.org/10.1016/0193-3973(94)90008-6

[46] Gee, J.P. (2007) Good Video Games + Good Learning. Peter Lang, New York. https://doi.org/10.3726/978-1-4539-1162-4

[47] http://www.philipbouchard.com/OT-book/OT-chapter14.html

[48] Annetta, L. (2008) Video Games in Education: Why They Should Be Used and How They Are Being Used. Theory into Practice, 47, 229-239. https://doi.org/10.1080/00405840802153940

[49] Singh, A., Agarwal, A. and Singh, Y.P. (2012) Remediating Self-Help Skill Deficits of Mentally Retarded Children through Computer Aided Instruction. BRICS Journal of Educational Research, 2, 120-127.

[50] Sharples, M., Taylor, J. and Vavoula, G. (2005) Towards a Theory of Mobile Learning.

[51] Breuer, J.S. and Bente, G. (2010) Why So Serious? On the Relation of Serious Games and Learning. Eludamos Journal for Computer Game Culture, 4, 7-24.

[52] Bourgonjon, J., Valcke, M., Soetaert, R. and Schellens, T. (2010) Students' Perceptions about the Use of Video Games in the Classroom. Computers \& Education, 54, 1145-1156. https://doi.org/10.1016/j.compedu.2009.10.022

[53] Bellotti, F., Berta, R., De Gloria, A. and Primavera, L. (2009) Enhancing the Educational Value of Video Games. Computers in Entertainment, 7, 23. https://doi.org/10.1145/1541895.1541903

[54] Gee, J.P. (2003) What Video Games Have to Teach Us about Learning and Literacy. Computers in Entertainment, 1, 20. https://doi.org/10.1145/950566.950595

[55] Kukulska-Hulme, A. (2009) Will Mobile Learning Change Language Learning? ReCALL, 21, 157-165. https://doi.org/10.1017/S0958344009000202

[56] Kukulska-Hulme, A. and Shield, L. (2008) An Overview of Mobile Assisted Language Learning: From Content Delivery to Supported Collaboration and Interaction. ReCALL, 20, 271-289. https://doi.org/10.1017/S0958344008000335

[57] Stockwell, G. (2008) Investigating Learner Preparedness for and Usage Patterns of Mobile Learning. ReCALL, 20, 253-270. https://doi.org/10.1017/S0958344008000232

[58] https://play.google.com/store/apps/details?id=air.Primary.Arabic.A4enc\&hl=ar

[59] https://play.google.com/store/apps/details?id=com.pescapps.gamekids2free

[60] http://school.panoramaon.com/books 
[61] El-Nasr, M.S., Drachen, A. and Canossa, A. (2016) Game Analytics. Springer, London.

[62] Laurillard, D. (2013) Rethinking University Teaching: A Conversational Framework for the Effective Use of Learning Technologies. Routledge, Abingdon-on-Thames. https://doi.org/10.4324/9781315012940

[63] Rossing, J., Miller, W.M., Cecil, A.K. and Stamper, S.E. (2012) iLearning: The Future of Higher Education? Student Perceptions on Learning with Mobile Tablets. Journal of the Scholarship of Teaching and Learning, 1, 1-26.

[64] Gould, D. (2003) Complete Maya Programming: An Extensive Guide to MEL and C++ API, Morgan Kaufmann.

[65] Barrilleaux, J. (2001) 3D User Interfaces with Java 3D. Manning, Greenwich.

[66] Checho, C. (2007) The Effects of Podcasting on Learning and Motivation: A Mixed Method Study of At-Risk High School Students. University of Nevada, Reno.

[67] Heim, M. (1994) The Metaphysics of Virtual Reality. Oxford University Press on Demand, Oxford. https://doi.org/10.1093/acprof:oso/9780195092585.001.0001

[68] Johnsen, K., Ahn, S.J., Moore, J., Brown, S., Robertson, T.P., Marable, A. and Basu, A. (2014) Mixed Reality Virtual Pets to Reduce Childhood Obesity. IEEE Transactions on Visualization and Computer Graphics, 20, 523-530. https://doi.org/10.1109/TVCG.2014.33

[69] Melissa Holland, V. (2013) Intelligent Language Tutors: Theory Shaping Technology. Routledge, Abingdon-on-Thames. https://doi.org/10.4324/9781315044811

[70] Swartz, M. and Yazdani, M. (2012) Intelligent Tutoring Systems for Foreign Language Learning: The Bridge to International Communication. Springer Science \& Business Media, Berlin, 80.

[71] Dodigovic, M. (2005) Artificial Intelligence in Second Language Learning: Raising Error Awareness. Multilingual Matters, Bristol, 13.

[72] Patel, M.F. and Jain, P.M. (2008) English Language Teaching. Sunrise Publishers and Distributors, Bangalore.

[73] Wahba, K. (2014) Handbook for Arabic Language Teaching Professionals in the 21st Century. Routledge, Abingdon-on-Thames. 